\title{
Effect of hydroxyapatite bioceramics on the growth of osteoblasts and HIF- $\alpha /$ VEGF signal axis in partial hypoxia environment in vitro
}

\author{
Yanyi Liu, Zekun Gan and Fei Hu* \\ Stomatological Hospital, Southern Medical University, Guangzhou, Guangdong, China
}

\begin{abstract}
.
BACKGROUND: Hydroxyapatite bioceramic is a kind of bone implant commonly used in oral clinic treatment. In the early stage of tissue repair, cells will suffer hypoxic due to the interruption of blood supply.

OBJECTIVE: Studying the expression of osteoblasts in hypoxic environment will help us to understand the expression and response mechanism of osteoblasts at the implantation site of hydroxyapatite in the early stage of hypoxia.

METHODS: MG63 osteoblast cell line was used in this study. The cells of normal group were incubated under normal oxygen and hydroxyapatite ceramics condition. The cells of hypoxia group were incubated under hypoxia $\left(37^{\circ} \mathrm{C}, 8 \% \mathrm{CO}_{2}, 8 \% \mathrm{O}_{2}, 86 \%\right.$ $\mathrm{N}_{2}$ ) and hydroxyapatite ceramics condition. Cell proliferation was measured by CCK8 assay. Apoptosis was measured by flow cytometry. Serum alkaline phosphatase (ALP) activity was measured by ALP kit. Hypoxia inducible factor (HIF- $\alpha$ ) and vascular endothelial growth factor (VEGF) were detected by Western blot.

RESULTS: Compared to the normal group, the cells of hypoxia group showed a dramatically higher proliferation ability, especially at $48 \mathrm{~h}(P<0.05)$. Due to hypoxia, cell apoptosis was induced, but there is no difference between these two groups. Interestingly, the ALP activity of hypoxia group was higher than that of normal group at $24 \mathrm{~h}$ and $48 \mathrm{~h}(P<0.05)$. Mechanically, western blot result showed that the protein level of both HIF- $\alpha$ and VEGF were up-regulated in hypoxia group.

CONCLUSIONS: Under hypoxia condition, hydroxyapatite bioceramics can promote the proliferation of MG63 osteoblasts, elevate the activity of alkaline phosphatase and upregulate HIF- $\alpha$ and VEGF expression without effect on apoptosis.
\end{abstract}

Keywords: Hypoxia inducible factor, hydroxyapatite, hypoxia, osteoblasts

\section{Introduction}

Hydroxyapatite bioceramics are rich in minerals, one of the most important components is hydroxyapatite crystal $\left[\mathrm{Ca}_{10}(\mathrm{PO} 4)_{6}(\mathrm{OH})_{2}\right][1]$. Amorphous calcium hydrogen phosphate $\left(\mathrm{CaHPO}_{4}\right), \mathrm{Ca}^{2+}, \mathrm{Mg}^{2+}$, $\mathrm{Na}^{+}, \mathrm{Cl}^{-}$, and $\mathrm{HCO}^{-}$were also adsorbed on it. Hydroxyapatite bioceramics are widely used in dental clinical treatment, such as alveolar bone reconstruction, filling of upper and lower alveolar bone defects, filling of alveolar bone protected bone powder, bone loss around implants and various problems of alveolar bone defects in orthodontic treatment $[2,3]$.

\footnotetext{
${ }^{*}$ Corresponding author: Fei Hu, Stomatological Hospital, Southern Medical University, Guangzhou, Guangdong 510280, China. E-mail: hf126@smu.edu.cn.
} 
In the process of hydroxyapatite bioceramic filling treatment, the oral alveolar bone environment is not a complete oxygen environment. In the early stage of bone defects, there is not enough oxygen for cell growth due to the limitation of local microcirculation. At this time, the adaptation of cells to hypoxia and the promotion of vascular intercellular response are crucial for bone regeneration and wound healing [4]. HIF- $\alpha$, an upstream factor of Vascular endothelial growth factor (VEGF), is highly expressed in hypoxic environment. HIF- $\alpha$ can promote the transcription of various angiogenic factors and enhance the adaptability of vascular endothelial cells in hypoxic environment [5]. VEGF, the most critical molecule to promote angiogenesis, is also expressed in osteoblasts. It promotes angiogenesis during bone regeneration by inducing the growth of endothelial cells, and plays an important role in maintaining the nutrient supply of new bone tissue and the excretion of metabolites [6].

Human osteosarcoma cells (MG63) are osteoblast like cells and belong to osteoblast cell line. Due to the limitation of passage times and cell source of primary osteoblasts, we selected osteoblast like cell line to replace primary cells in our study. In this study, we found that, under hypoxia condition, hydroxyapatite bioceramics can promote the proliferation of MG63 osteoblasts, elevate the activity of alkaline phosphatase and upregulate HIF- $\alpha$ and VEGF expression. This study may provide a theoretical basis for the clinical application of hydroxyapatite ceramics in promoting bone regeneration under hypoxia.

\section{Materials and method}

\subsection{Cell culture}

Human osteosarcoma cells (MG63) were cultured in Dulbecco's Modified Eagle Medium (DMEM) (Gibco, AE29040273) plus 10\% fetal bovine serum (FBS) (Gibco, 2045677RP) and 1\% penicllinstreptomcyin (P/S) (Gibco, 2068817). Under normal conditions, all cells were cultured at $37^{\circ} \mathrm{C}$ with $5 \%$ $\mathrm{CO}_{2}$, and $95 \%$ humidity. Cells were passaged every 2 days.

\subsection{Preparation of hydroxyapatite bioceramics}

Hydroxyapatite bioceramics were synthetized by Beijing Yihuajian science and Trade Co., Ltd., China, and extracted according to the scheme in part 12 of ISO10993.12-2008 biological evaluation of medical devices. The stocking concentration of hydroxyapatite bioceramic is $0.2 \mathrm{~g} / \mathrm{ml}$. Briefly, to dissolve the hydroxyapatite bioceramics, $0.2 \mathrm{~g}$ hydroxyapatite bioceramics were added into $1 \mathrm{ml}$ intact medium and extracted in inert container at $37^{\circ} \mathrm{C}$ for 5 days.

\subsection{Cell proliferation assay}

MG63 cells were cultured in serum-free medium in 96 well plate for 24 hours. The number of cells per well was $1 \times 10^{4}$. Next, the cells of the normal group were cultured under normal oxygen and hydroxyapatite ceramics. The cells in hypoxia group were cultured under hypoxia $\left(37^{\circ} \mathrm{C}, 8 \% \mathrm{CO}_{2}, 8 \%\right.$ $\mathrm{O}_{2}, 86 \% \mathrm{~N}_{2}$ ) and hydroxyapatite ceramics. The cells were then treated with hydroxyapatite bioceramics for 24 hours. After that, add 10 to each well $\mu$ L CCK-8 solution (China Kaiji Biotechnology Co., Ltd.). The cells were cultured for 4 hours, 8 hours, 24 hours and 48 hours respectively. The final reaction product was evaluated by a microplate reader for absorbance at a wavelength of $450 \mathrm{~nm}$. 


\subsection{Apoptosis assay}

MG63 cells were plated at $6 \mathrm{~cm}$ dish with the density of $4 \times 10^{5} / \mathrm{dish}$. After relative treatment, collected the cells as follows: briefly, cells were washed with PBS for once and treated the cell with $0.25 \%$ trypsin for $1 \mathrm{~min}$, then added the medium to neutralize the trypsin. Centrifuged at $1000 \mathrm{rpm}, 5 \mathrm{~min}$, RT and then got the cell pellets. Added $50 \mu \mathrm{l}$ binding buffer, and mixed well. Added $2.5 \mu \mathrm{l}$ Annexin V-FITC + $2.5 \mu \mathrm{l}$ Propidium iodide (PI), and incubated cells at room temperature for $15 \mathrm{~min}$. After centrifugation at $1000 \mathrm{rpm}$ for $5 \mathrm{~min}$, the supernatant was discarded. Added $300 \mu \mathrm{l}$ binding buffer to resuspend the cell pellets, and then analyzed by the BD FACS Canto analytic flow cytometer.

\subsection{ALP activity assay}

MG63 cells were plated at $6 \mathrm{~cm}$ dish with the density of $4 \times 10^{5} / \mathrm{dish}$. After relative treatment, collected the cell lysate and evaluated the ALP activity according to the manufacturer's instructions. Briefly, diluted the cell lysates with PBS, and then added assay buffer to the diluted sample, and incubated in water bath with $37^{\circ} \mathrm{C}$ for $15 \mathrm{~min}$. After that, stopped the reaction, and the final reaction product was evaluated by a microplate reader for absorbance at a wavelength of $405 \mathrm{~nm}$.

\subsection{Western blot analysis}

The cell lysates of MG63 cells were lyzed in ice-cold RIPA buffer. Protein concentrations of the cell lysates were determined by Bradford Protein assay (BCA). $20 \mu \mathrm{g}$ of protein per lane was diluted in the standard SDS-sample buffer and subjected to electrophoresis on 10\% SDS-polyacrylamide gels. Proteins were then transferred to an immobilon PVDF membrane, blocked with 5\% milk in TBST (20 mM Tris, $150 \mathrm{mM} \mathrm{NaCl}, \mathrm{pH} 7.6,0.1 \%$ Tween20) for $2 \mathrm{~h}$, and incubated with the primary antibody (1:1000 dilution) at $37^{\circ} \mathrm{C}$ for $2 \mathrm{~h}$. After washing with TBST for three times, the blots were probed with a secondary antibody (1:5000 dilution) at $37^{\circ} \mathrm{C}$ for $2 \mathrm{~h}$ and then for detected by film. HIF antibody (proteintech, 20960-1-AP), VEGF antibody (proteintech, 66828-1-Ig).

\subsection{Statistical analysis}

All the represent data from three independent experiments. The results were presented as the mean \pm standard deviation. One-way ANOVA was performed to determine the differences among grouped data. $P<0.05$ indicates statistically significant.

\section{Results}

\subsection{Hydroxyapatite bioceramics promoted cell proliferation under hypoxia condition}

The cell proliferation activity was evaluated by CCK 8 assay in the co-culture system at $4 \mathrm{~h}, 8 \mathrm{~h}, 24 \mathrm{~h}$ and $48 \mathrm{~h}$, respectively. The results showed that under hypoxia condition, hydroxyapatite bioceramics can promote the proliferation of MG63 osteoblasts $(P<0.05)$. Consistently, the cell proliferation rate increased much more significantly along with the extension of cell culture time (Fig. 1).

\subsection{Hydroxyapatite bioceramics showed no obvious effect on apoptosis}

The apoptosis assay was conducted by Annexin V-FITC and PI double staining, the result of which 
Table 1

ALP activity protein in each group (per mg)

\begin{tabular}{lcc}
\hline Group & Mean \pm stdev & $t$-test \\
\hline Normal group 24 h & $2.823 \pm 0.043$ & \\
Hypoxia group 24 $\mathrm{h}^{*}$ & $3.555 \pm 0.162$ & 0.010 \\
Normal group 48 $\mathrm{h}$ & $2.667 \pm 0.077$ & \\
Hypoxia group 48 $\mathrm{h} *$ & $3.188 \pm 0.060$ & 0.020 \\
\hline
\end{tabular}

CCK8 Test

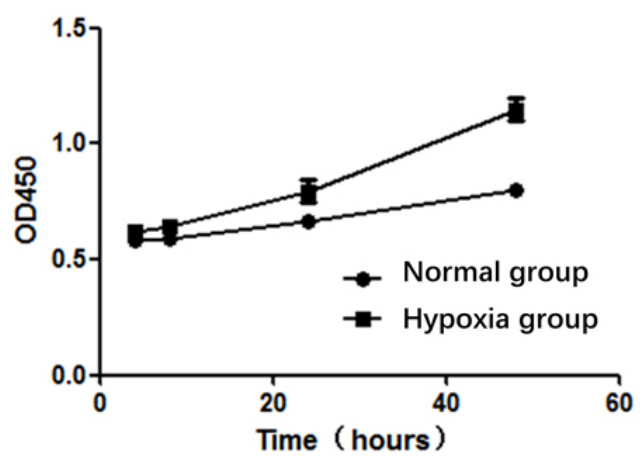

Fig. 1. Hydroxyapatite bioceramics promoted cell proliferation under hypoxia condition.

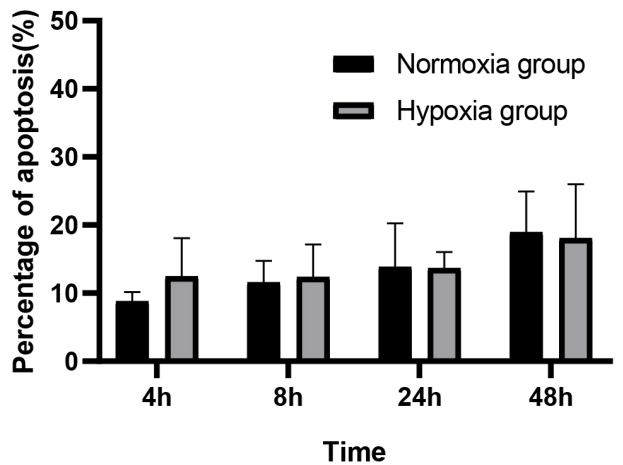

Fig. 2. Hydroxyapatite bioceramics showed no obvious effect on apoptosis.

was read out by flow cytometer. The result showed that there was no significant difference in apoptosis between normal group and hypoxia group at 4 h, 8 h, $24 \mathrm{~h}$ and $48 \mathrm{~h}$, respectively (Fig. 2). This may be due to the adaptability of cells in hydroxyapatite co-culture system.

\subsection{Hydroxyapatite bioceramics elevated ALP activity under hypoxia condition}

Alkaline phosphatase (ALP) is a specific marker of osteoblast maturation, and is a common index to evaluate the secretion function of osteoblasts. In this study, the alkaline phosphate activity of MG63 osteoblast like cells was detected at $24 \mathrm{~h}$ and $48 \mathrm{~h}$. The data from Table 1 showed that the activity of ALP in hypoxia group was higher than that in normal group $(P<0.05)$, which indicated that the differentiation 

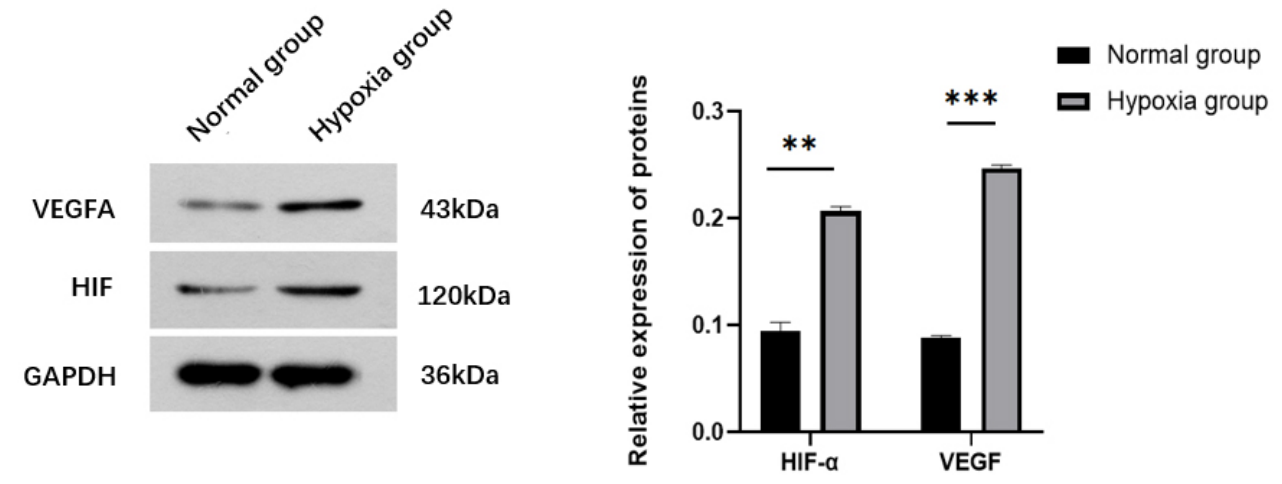

Fig. 3. Hydroxyapatite bioceramics upregulated the protein levle of HIF-VEGF signal axis.

ability of osteoblasts and the bone metabolism of osteoblast like cells under hypoxia condition are more active than that in normoxia condition.

\subsection{Hydroxyapatite bioceramics upregulated the protein levle of HIF-VEGF signal axis}

Mechanically, as shown in Fig. 3, the western blot result showed that after treatment with hydroxyapatite bioceramics for $24 \mathrm{~h}$, the protein level of both HIF- $\alpha$ and VEGF were up-regulated in hypoxia group.

\section{Conclusion}

Hydroxyapatite bioceramics is a kind of bone implant material, and is commonly used in oral clinic. Hydroxyapatite bioceramics account for $60 \%$ of the extracellular matrix of the skeleton, and its chemical composition and crystal structure are very similar to the skeleton [7]. It not only supports the attachment of osteoblasts to bone, but also has strong osteoinductive properties. Studies have proved that it shows good osteogenic ability in the aspects of maxillary sinus wall defect, tissue defect after tumor removal or bone absorption around implant [8,9]. In tissue engineering, cells can sense the changes of external conditions through their own biological signals and adapt to the changes of external materials and environment. A large number of in vitro experiments show that hydroxyapatite has good differentiation and proliferation effects on osteoblasts and stromal cells [10-12]. In the preparation of some tissue engineering scaffolds, hydroxyapatite is often used to promote the growth of bone cells $[13,14]$. In the early stage of tissue repair, tissue cells will suffer partial hypoxic microenvironment in bone defect site due to blood supply interruption [15]. Studying the expression of osteoblasts in partial hypoxia environment will help us understand the behavior and mechanism of osteoblasts induced by partial hypoxia in the presence of hydroxyapatite bioceramics, so as to help us understand the cellular reaction and improve the properties of materials.

In this study we confirmed that under hypoxia condition, hydroxyapatite bioceramics can promote the proliferation of MG63 osteoblasts. Consistently, the cell proliferation rate increased much more significantly along with the extension of cell culture time (Fig. 1). However, it showed no effects on apoptosis, which may be related to the adaptability of cells in hydroxyapatite co culture system. ALP is a biochemical and histological marker to identify osteoblasts, and its activity reflects the differentiation and functional status of osteoblasts to a certain extent [16]. We found that the ALP activity of osteoblasts in hypoxia group was higher than that in normoxia group at $24 \mathrm{~h}$ and $48 \mathrm{~h}$, indicating that the differentiation 
ability of osteoblasts and the bone metabolism of osteoblast like cells under hypoxia condition are more active than that in normoxia condition. Hypoxia inducible factor (HIF) is a heterodimeric protein composed of the constitutive subunit HIF- $1 \beta$ and the oxygen-regulated subunit HIF- $1 \alpha$, and transmits hypoxia signal and mediates the expression of hypoxia effect under hypoxia conditions. By combining with hypoxia related response elements, HIF can stimulate the expression of downstream related genes such as VEGF, and plays a crucial role in angiogenesis, erythropoiesis, energy metabolism and cell cycle [17]. It has been reported that HIF-1 protein can specifically bind to the hypoxia response element of erythropoietin gene, activate VEGF, and increase the blood supply and oxygen supply of osteoblasts [18]. Related studies have shown that VEGF can inhibit cell apoptosis and improve cell growth [19]. In our study, we found that the HIF and VEGF protein levels in hypoxia group were relatively up-regulated, indicating that HIF can be increased in the co-culture system of hydroxyapatite and osteoblast like cells under hypoxia condition, and then HIF can indirectly elevate the expression of VEGF to promote osteogenesis.

We found that hydroxyapatite ceramics can promote cell proliferation and differentiation in the early stage of culture under hypoxia condition $\left(37^{\circ} \mathrm{C}, 8 \% \mathrm{CO}_{2}, 8 \% \mathrm{O}_{2}, 86 \% \mathrm{~N}_{2}\right)$, which might be regulated by HIF- $\alpha$ /VEGF signaling pathway. Due to the limitations of experimental conditions, we did not set more oxygen concentration groups for comparison. In the following studies, we will further explore the effect of hydroxyapatite on osteoblast related cells under different hypoxia concentrations both in vitro and in vivo, and investigate that hypoxia hydroxyapatite bioceramics does have a unique effect in HIF- $\alpha$ /VEGF signaling pathway.

\section{Conflict of interest}

The authors state that there is no conflict of interest related to this article.

\section{References}

[1] Azizi F, Heidari F, Fahimipour F, Sajjadnejad M, Vashaee D, Tayebi L. Evaluation of mechanical and biocompatibility properties of hydroxyapatite/manganese dioxide nanocomposite scaffolds for bone tissue engineering application. International Journal of Applied Ceramic Technology. 2020; 17(5).

[2] Gradinaru S, Popescu V, Leasu C, Pricopie S, Yasin S, Ciuluvica R, Ungureanu E. Hydroxyapatite ocular implant and non-integrated implants in eviscerated patients. J Med Life. 2015 Jan-Mar; 8(1): 90-3.

[3] Sakamoto Y, Sakamoto T, Ishii T, Kishi K. Assessment of bioabsorbable hydroxyapatite for secondary bone grafting in unilateral alveolar clefts. Cleft Palate Craniofac J. 2020 Jan; 57(1): 114-117.

[4] Yellowley CE, Genetos DC. Hypoxia signaling in the skeleton: Implications for bone health. Curr Osteoporos Rep. 2019 Feb; 17(1): 26-35.

[5] Branco-Price C, Evans CE, Johnson RS. Endothelial hypoxic metabolism in carcinogenesis and dissemination: HIF-A isoforms are a NO metastatic phenomenon. Oncotarget. 2013 Dec; 4(12): 2567-76.

[6] Hu K, Olsen BR. Osteoblast-derived VEGF regulates osteoblast differentiation and bone formation during bone repair. J Clin Invest. 2016 Feb; 126(2): 509-26.

[7] Guillen-Romero LD, Oropeza-Guzmán MT, López-Maldonado EA, Iglesias AL, Paz-González JA, Ng T, Serena-Gómez E, Villarreal-Gómez LJ. Synthetic hydroxyapatite and its use in bioactive coatings. J Appl Biomater Funct Mater. 2019 Jan-Mar; 17(1).

[8] Khaled H, Atef M, Hakam M. Maxillary sinus floor elevation using hydroxyapatite nano particles vs tenting technique with simultaneous implant placement: A randomized clinical trial. Clin Implant Dent Relat Res. 2019 Dec; 21(6): 1241-1252.

[9] Zhang K, Zhou Y, Xiao C, Zhao W, Wu H, Tang J, Li Z, Yu S, Li X, Min L, Yu Z, Wang G, Wang L, Zhang K, Yang X, Zhu X, Tu C, Zhang X. Application of hydroxyapatite nanoparticles in tumor-associated bone segmental defect. Sci Adv. 2019 Aug 2; 5(8). 
[10] Ersoy B, Bayramiçli M, Ercan F, Şrinoıglu H, Turan P, Numanoğlu A. Comparison of bone prefabrication with vascularized periosteal flaps, hydroxyapatite, and bioactive glass in rats. J Reconstr Microsurg. 2015 May; 31(4): 291-9.

[11] Canettieri AC, Colombo CE, Chin CM, Faig-Leite H. Femur bone repair in ovariectomized rats under the local action of alendronate, hydroxyapatite and the association of alendronate and hydroxyapatite. Int J Exp Pathol. 2009 Oct; 90(5): 520-6.

[12] Vamze J, Pilmane M, Skagers A. Biocompatibility of pure and mixed hydroxyapatite and $\alpha$-tricalcium phosphate implanted in rabbit bone. J Mater Sci Mater Med. 2015 Feb; 26(2): 73.

[13] Ramesh N, Moratti SC, Dias GJ. Hydroxyapatite-polymer biocomposites for bone regeneration: A review of current trends. J Biomed Mater Res B Appl Biomater. 2018 Jul; 106(5): 2046-2057.

[14] Chen P, Liu L, Pan J, Mei J, Li C, Zheng Y. Biomimetic composite scaffold of hydroxyapatite/gelatin-chitosan core-shell nanofibers for bone tissue engineering. Mater Sci Eng C Mater Biol Appl. 2019 Apr; 97: 325-335.

[15] Zuo X, Li J, Han X, Liu X, He H. Hypoxia inducible factor-1 $\alpha$. Prevention and Treatment of Oral Diseases, 2021; 29(7): 449-455.

[16] Topal İ, Gümüş B. Can Bone-Specific Alkaline Phosphatase and Osteocalcine Levels Be Used to Determine the Age in Children? Am J Forensic Med Pathol. 2020 Sep; 41(3): 182-187.

[17] Branco-Price C, Evans CE, Johnson RS. Endothelial hypoxic metabolism in carcinogenesis and dissemination: HIF-A isoforms are a NO metastatic phenomenon. Oncotarget. 2013 Dec; 4(12): 2567-76.

[18] Zhang S, Yuan Y, Zou J. Hypoxia inducible factor $1 \alpha$ Progress in the regulation of bone metabolism and angiogenesis in bone microenvironment. Chinese Journal of Osteoporosis. 2020; 26(8): 1201-1206.

[19] Debnath S, Mukherjee A, Saha D, Dash J, Chatterjee TK. Poly-l-Lysine inhibits VEGF and c-Myc mediated tumorangiogenesis and induces apoptosis in 2D and 3D tumor microenvironment of both MDA-MB-231 and B16F10 induced mice model. International Journal of Biological Macromolecules. 2021; 183. 